\title{
Health Seeking Behaviours of Patients Attending Primary Eye Care Centre in Nigeria
}

\author{
Emmanuel Olu Megbelayin1*, Yewande Olubunmi Babalola ${ }^{2}$ \\ ${ }^{1}$ Department of Ophthalmology, University of Uyo Teaching Hospital, Uyo, Nigeria \\ ${ }^{2}$ Department of Ophthalmology, University College Hospital, Ibadan, Nigeria \\ Email: favouredolu@yahoo.com
}

Received 9 April 2015; accepted 27 April 2015; published 6 May 2015

Copyright (C) 2015 by authors and OALib.

This work is licensed under the Creative Commons Attribution International License (CC BY). http://creativecommons.org/licenses/by/4.0/

\section{(c) (i) Open Access}

\section{Abstract}

Purpose: To determine health seeking behaviour in relation to non-orthodox eye medication use among patients attending a primary eye health center in Nigeria. Materials and Methods: It was a cross-sectional study of consecutive respondents. Participants' socio-demographic profile, types and pattern of harmful traditional eye medications (HTEMs) use were obtained using a pre-tested questionnaire. Data analysis was by SPSS version 20.0. Results: Of the 303 patients enrolled in the study, $153(50.5 \%)$ were males and $150(49.5 \%)$ were females. The age range was from 13 years old to 94 years old with a mean of $53.8 \pm 17.05$ years old. Majority of the subjects $(74.3 \%)$ used orthodox medical outfits for their eye care needs. The prevalence of use of HTEMs was $11.9 \%$. Common forms of TEMs used were herbs $24(66.7 \%)$, sugar water $3(8.3 \%)$, breast milk $3(8.3 \%)$ and onions $6(16.7 \%)$. There was statistically significant association between age and use of HTEMs $\left(p=604.27, \chi^{2}=<0.001,95 \%\right.$ CI $\left.=0.000-0.010\right)$, and health seeking behaviour $(p=$ 808.70, $\left.\chi^{2}=<0.001,95 \% \mathrm{CI}=0.000-0.010\right)$. Conclusion: Eye care providers and health care managers must have good knowledge of the various factors that negatively influence utilization of eye care services and be responsive to them.

\section{Keywords}

HTEMs, Chemists, Hospital, Behaviours

Subject Areas: Ophthalmology

${ }^{*}$ Corresponding author. 


\section{Introduction}

Crucial to achieving the goals of Vision 2020 is the extent of eye care service utilization which is influenced by health seeking behaviour. This in turn is affected by traditional practices, beliefs, fatalistic attitudes towards blindness and fear of outcome of medical or surgical interventions [1] [2]. Non-utilization of eye care facility could lead to increase in prevalence of avoidable blindness [2]-[4]. Dearth of modern eye facilities especially in rural communities results in search of alternative sources of care, including traditional healers and patent medicine sellers who serve as frontline health workers in these areas [5].

Non-availability is not the only barrier to utilization of eye care services, even where such services were available and at door-step. Omotoye et al. [2] reported apathy of those in dire need. Additionally, ignorance about causes of blindness and its treatment, socio-economic status, lack or uneven spread of trained manpower determine patients' choice of eye service provider [1] [5] [6]. Non-orthodox eye medications have continued to be patronized because of their ready availability, cheapness, inaccessible primary eye care services, trust and confidence in traditional healers, presumed failure of modern medicine to cure eye diseases, communication gap between patients and orthodox eye care providers, and influence of friends and relations [2] [7]-[9].

It appears eye health education is yet to permeate nooks and crannies of African societies to affect the right healthy habits. Effective eye health promotion involves a combination of three components: health education directed at behaviour change to increase adoption of prevention behaviours and uptake of services; improvements in health services such as the strengthening of patient education and increased accessibility and acceptability; and advocacy for improved political support for eye care services [10].

As part of efforts to promote healthy eye habits and enhance eye service utilization through appropriate health education, this study sought to critically explore eye health seeking behaviour in relation to non-orthodox eye medication use in one of the most patronized eye health facilities in our environment. It is hoped that knowledge gained from this study will help in the design of appropriate health education techniques. This will consequently improve quality and uptake of eye health services in our environment and in similar settings around the world.

\section{Materials and Methods}

\subsection{Study Area}

The study was carried out in a primary eye center, located in Abak, a rural town and the head-quarter of Abak Local Government Area of Akwa-Ibom State, Nigeria. With a landmass of $190 \mathrm{~km}^{2}$, It lies between $4^{\circ} 59^{\prime} \mathrm{N}$ and $7^{\circ} 47^{\prime} \mathrm{E}$ in the tropical rain forest belt of south-south Nigeria.

\subsection{Study Design}

It was a descriptive cross-sectional study.

\subsection{Study Population}

All involved patients are capable of responding to the pre-tested interviewer administered questionnaires.

\subsection{Sampling Technique}

All consenting consecutive patients were recruited into the study until the estimated sample size was attained.

\subsection{Sample Size Calculation}

\section{Formula}

To determine the sample size of this cross-sectional study, the following formula [11] was used:

$$
N_{f}=\frac{n}{1+\frac{n}{N}}
$$

$N_{f}=$ the desired sample size when the population is less than 10,000;

$n=$ the desired sample size when the population is more than 10,000;

$N=$ the estimate of the population size. 


\section{Calculation}

$n=$ was calculated to be 400 ;

$N$ = the estimated population of the patients for a month was 1000 when the study was expected to last.

Substituting in the equation above:

$$
N_{f}=\frac{400}{1+\frac{400}{1000}}=\frac{400}{1.4}=286
$$

$5 \%$ (14) attrition rate was added making the minimum sample size to be 300 .

\subsection{Study Instruments}

A structured questionnaire was used to obtain data.

\subsection{Instrument Validity}

The questionnaire was checked for internal validity using SPSS (Statistical Package for Social Sciences) version 20.0. Average Cronbach alpha analysis was 0.84 .

\subsection{Pilot Study}

A questionnaire was designed in line with study's objectives. A pilot study was conducted in a similar health institution but in a different Local Government of Akwa Ibom State to test and fine-tune research tool and train the interviewer.

\section{Main Study}

\subsection{Community Entry}

Proper community entry was done through prior visits and discussions with the head of the institution. The purpose and the advantages of the study were enumerated and confidentiality was guaranteed. Days of the week when large patient turn-out was likely were determined and chosen.

\subsection{Inclusion Criteria}

Participants must be registered patients, must grant consent and must be able to respond to the questionnaire with or without the aid of assistance who might be an interpreter.

\subsection{Exclusion Criteria}

Patients who were yet to be registered or who was too young to respond to the questions contained in the questionnaire were excluded.

\subsection{Ethical Consideration}

Study was in line with Helsinki declaration of 1964 and as subsequently amended. Those interviewed consented without being coerced or threatened that they will not be attended to unless they oblige.

\subsection{Process of Data Collection}

The author and a trained assistant administered the questionnaire. Information obtained included demographic data such as age, sex, and occupation. Other vital statistics such as level of education, health seeking behaviour were also determined. Other details included participants’ HTEM use profile.

\subsection{Data Management}

Data was entered into a computer after coding and analyzed using SPSS version 20.0. Descriptive analysis was used to generate frequency tables, means, and standard deviation. Bivariate analysis of categorical variables was 
done. The level of significance was derived with chi-square test, confidence interval set at $95 \%$ and $p$ value $<$ 0.05 .

\subsection{Results and Data Analysis}

Of the 303 patients enrolled in the study, 1353 (50.5\%) were males and 150 (49.5\%) were females. The age range was from 13 years old to 94 years old with a mean of $53.8 \pm 17.05$ years old. Occupation and educational levels of the subjects are as shown in Table 1 and Table 2 respectively. Figure 1 shows age distribution by sex. Figure 2 and Figure 3 show health seeking behaviours and pattern of HTEMs use respectively. Majority of the subjects (74.3\%) used orthodox medical outfits for their eye care needs. The prevalence of use of HTEMs was 11.9\%. Common forms of TEM used were herbs 24 (66.7\%), sugar water $3(8.3 \%)$, breast milk $3(8.3 \%)$ and onions $6(16.7 \%)$. There was statistically significant association between age and use of HTEMs ( $p=604.27$, $\left.\chi^{2}=<0.001,95 \% \mathrm{CI}=0.000-0.010\right)$ but none with sex $\left(p=7.81, \chi^{2}=0.115,95 \% \mathrm{CI}=0.114-0.195\right)$. Similarly, the age of participants determined health seeking behaviours $\left(p=808.70, \quad \chi^{2}=<0.001,95 \% \mathrm{CI}=\right.$ $0.000-0.010)$ but not the sex $\left(p=3.19, \chi^{2}=0.46,95 \% \mathrm{CI}=0.404-0.518\right)$. The level of education was statistically associated with use of HETMs $\left(p=36.90, \chi^{2}=0.13,95 \% \mathrm{CI}=0.000-0.026\right)$ and health seeking behaviours ( $\left.p=31.90, \chi^{2}=0.007,95 \% \mathrm{CI}=0.000-0.016\right)$. Occupation was found to be associated with both use of HTEM ( $p=74.25, \chi^{2}=<0.001,95 \%$ CI, $\left.0.000-0.010\right)$ and eye health seeking behaviours $(p=48.38$, $\left.\chi^{2}=0.0001,95 \% \mathrm{CI}=0.000-0.010\right)$

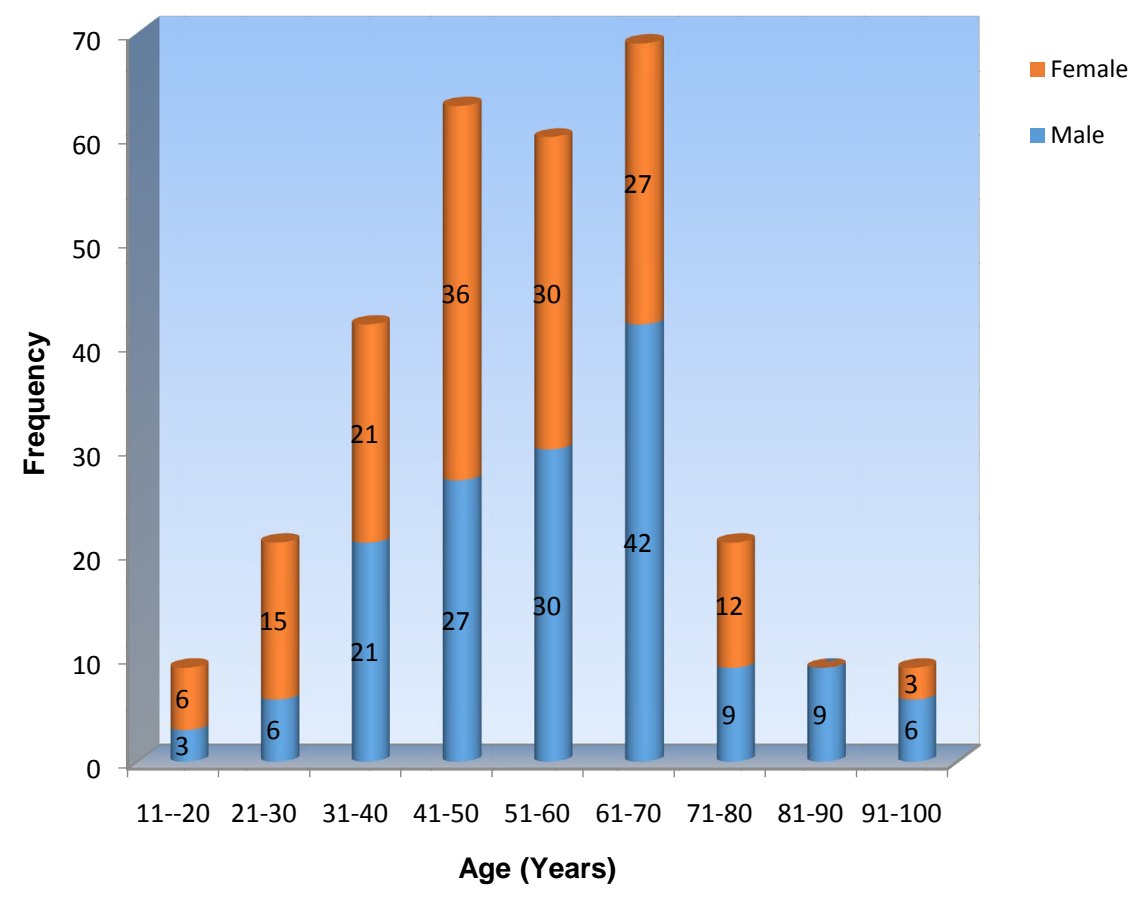

Figure 1. Age distribution by sex.

Table 1. Occupation.

\begin{tabular}{ccc}
\hline Occupation & Frequency & Percent \\
\hline Farming & 36 & 11.9 \\
Artisan & 81 & 26.7 \\
Business & 63 & 20.8 \\
Civil servant & 42 & 13.9 \\
Student & 21 & 6.9 \\
Pensioner/retired & 36 & 11.9 \\
None & 24 & 7.9 \\
Total & $\mathbf{3 0 3}$ & $\mathbf{1 0 0 . 0}$ \\
\hline
\end{tabular}




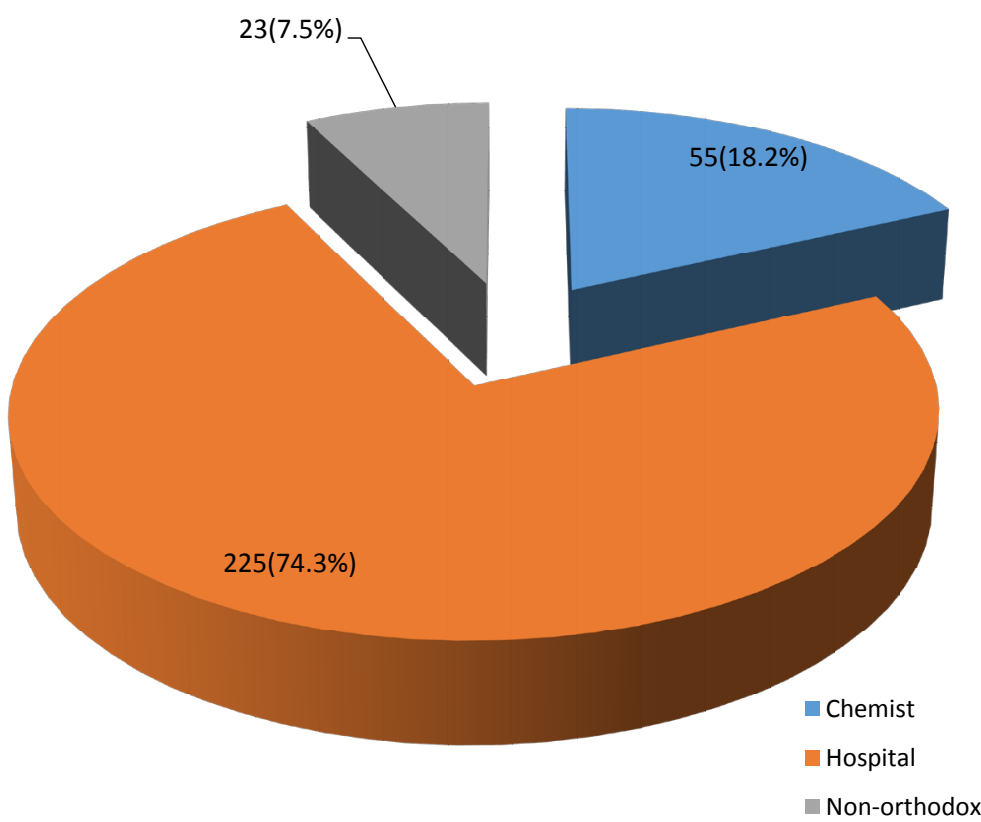

Figure 2. Health seeking behaviours.

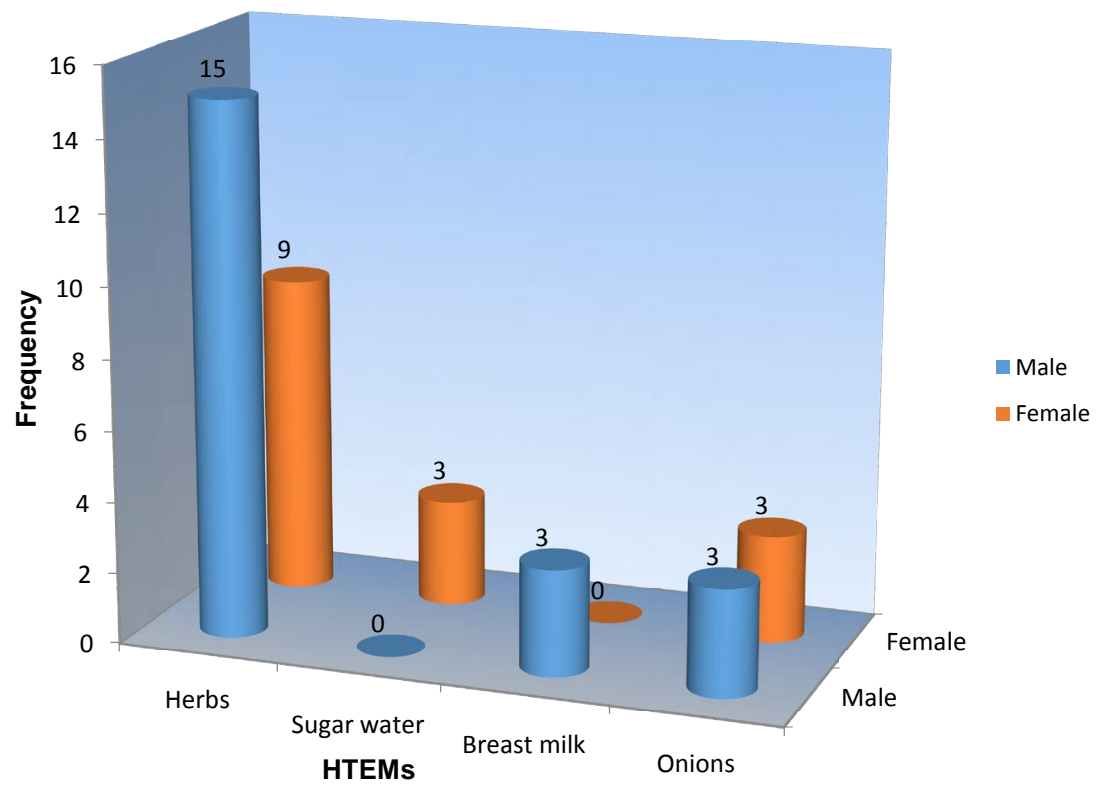

Figure 3. TEMs applied to the eyes.

Table 2. Levels of education.

\begin{tabular}{ccc}
\hline Education & Frequency & Percent \\
\hline Primary & 117 & 38.6 \\
Secondary & 150 & 49.5 \\
Tertiary & 27 & 8.9 \\
None & 9 & 3.0 \\
Total & $\mathbf{3 0 3}$ & $\mathbf{1 0 0 . 0}$ \\
\hline
\end{tabular}




\section{Discussion}

Key to the realization of the VISION 2020 initiative is the extent to which the available health services are accessed. Worldwide, the last two decades have witnessed a phenomenal increase in the prevalence of use of TEM [12] [13]. Despite lack of sound scientific basis to justify the use, in Africa, the use of non-orthodox eye medications which are mostly injurious to the eyes is common [14]-[16]. Epidemiological studies have documented diverse prevalent figures of TEM use [7] [8] [13] [17] [18]. The prevalence of HTEMs use in our respondents was $11.9 \%$. This figure is lower than previous prevalence figures: $44.2 \%$ (Atyak, Uganda) and 47.7\% (Southern India) probably due to increasing health awareness [8] [13]. Extracts from plants appear to be the commonly patronized traditional medications across various studies in many countries [9] [13]. We recorded 66.6\% (24/36), with lower figures reported by Prajna et al. (29.6\%) and Eze et al. (37.7\%) [9] [13].

In this study, about $12 \%$ of the respondents relied on subsistence agriculture for livelihood, reflecting low socioeconomic status with a possible bearing on the affordability of modern eye health care services. This may have had an important implication on an increased chance of this population using traditional eye health practices as an alternative. More men applied herbs into their eyes suggesting that ocular injuries sustained during the course of farming could have been treated with herbs.

About $63.4 \%$ of the respondents were 50 years old and above which was similar to $60.3 \%$ reported in Ekiti but at variance with 33\% and 44\% reported in Ogun and Oyo respectively [2] [19] [20]. Discrepancies observed may partly be explained on the different sample sizes, scopes and delimitations of the studies. Again patients' perception of competencies and strengths of health facilities have tendency to attract a category of eye health seekers. For instance, the center the current study conducted is reputed for good cataract surgical outcome with a likelihood of attracting older patients who had cataract.

The age of our patients determined where and how they meant their eye health needs. This agreed with a South Indian study where Kovai et al. found a significant association between age and noticeable decrease in vision [21]. It was suggested that this might be due to the health seeking priorities in relation to age in rural areas, as age influenced the decision to seek health. However, the reports on the effect of gender on eye care utilization have been inconsistent [22] [23]. The current study showed no gender difference in the use of HTEMs and eye health seeking attitude. Similar findings have been reported by studies among rural Irish and Indian populations [13] [23].

The association between education and utilization of modern health facilities has not been uniform across studies [2] [4] [8] [21] [24]-[26]. Greater health consciousness and stronger economic powers could be linked with why educated individual will seek orthodox eye care as observed in some studies [4] [21] [24] [26], the current study inclusive. A few other studies have reported a similar health seeking behaviour among educated and those without formal education [8] [15]. Perhaps norms, socio-cultural practices and other unforeseeable circumstances could influence individual's choice of health intervention in moments of despair, pain and ill-health regardless of level of education.

\section{Conclusion}

TEM use will continue so long as wrong attitude to health and unavailable primary eye care persist among the majority of the population of Africa. This can be minimized by two-prong approach of incorporating eye health education within the framework of existing primary health program and establishment of outreach centers in rural areas by secondary and tertiary eye centers.

\section{Recommendations}

1. Active collaboration between orthodox eye care providers and traditional medical practitioners can produce synergistic outcome for effective eye health delivery.

2. Intensive health education can be provided to create awareness in the community of the dangers of using traditional medicine on red or discharging eyes.

3. Patient focused and community based health education strategies should be designed by relevant government authorities to address the misconception about causation and cure of certain eye diseases.

4. Medicinal plants commonly used to treat eye diseases should be scientifically analyzed to determine their pharmaco dynamics properties.

5. There is a need for strengthening of eye care programs and even distribution of eye care resources. 


\section{Limitations of the Study}

The limitations of this study need to be pointed out. Being a hospital-based study, the responses of the participants cannot be said to be totally objective. Perhaps if the study was conducted outside the hospital environment, the atmosphere might be conducive for non-biased submissions. Generalization of the findings from the current study to the larger society must be with caution because the opinions sought bothered on attitudes and practices which may have been grossly under-reported in a bid to appease the interviewers.

\section{References}

[1] Keeffe, J.E., Weih, L.M., McCarty, C.A. and Taylor, H.R. (2002) Utilization of Eye Care Services by Urban and Rural Australia. British Journal of Ophthalmology, 86, 24-27. http://dx.doi.org/10.1136/bjo.86.1.24

[2] Omotoye, J.O., Onakpoya, O.H., Ajayi, A.I., Ajayi, A.E. and Ajite, K.O. (2013). Bilateral Blindness: Prevalence and Their Utilization of Existing Eye Care Facilities in a Nigerian Rural Community. IOSR Journal of Dental and Medical Sciences, 9, 54-59. http://dx.doi.org/10.9790/0853-0925459

[3] Oduntan, A.O., Nthangeni, M.E., Ramudzuli, M.R. and Madu, S.N. (2003) Causes and Prevalence of Low Vision and Blindness in Black South African Adults in the Limpopo Province. SA J Optm, 62, 8-15.

[4] Fotouhi, A., Hashemi, H. and Mohammed, K. (2006) Eye Care Utilization Patterns in Tehran Population: A Population Based Cross-Sectional Study. BMC Ophthalmology, 6, 4-12.

[5] Ashaye, A., Ajuwon, A.J. and Adeoti, C. (2006) Perception of Blindness and Blinding Eye Conditions in Rural Communities. Journal of the National Medical Association, 98, 887- 893.

[6] Lewallen, S. and Courtright, P. (2000) Recognizing and Reducing the Barrier to Cataract Surgery. Community Eye Health, 13, 20-21.

[7] Mselle, J. (1998) Visual Impact of Using Traditional Medicine on the Injured Eye in Africa. Acta Tropica, 70, 185192.

[8] Nyathirombo, A., Mwesigye, F. and Mwaka, A. (2012) Traditional Eye Health Practices in Atyak Sub-County, Nebbi District Uganda. East African Journal of Ophthalmology, 16, 29-34.

[9] Eze, B.I., Chuka-Okosa, C.M. and Uche, J.N. (2009) Traditional Eye Medicine Use by Newly Presenting Ophthalmic Patients to a Teaching Hospital in South-Eastern Nigeria: Socio-Demographic and Clinical Correlates. BMC Complementary and Alternative Medicine, 9, 40.

[10] Hubley, J. and Gilbert, C. (2006) Eye Health Promotion and the Prevention of Blindness in Developing Countries: Critical Issues. British Journal of Ophthalmology, 90, 279-284. http://dx.doi.org/10.1136/bjo.2005.078451

[11] Araoye, M.O. (2004) Research Methodology with Statistics for Health and Social Sciences. In: Subject Selection, Nathadex Publishers, Ilorin, 115-120.

[12] Osahon, A.I. (1995) Consequences of Traditional Eye Medication in U.B.T.H., Benin City. Nigerian Journal of Ophthalmology, 3, 51-54.

[13] Prajna, N.V., Pillai, M.R., Manimegalai, T.K. and Srinivasan, M. (1999) Use of Traditional Eye Medicines by Corneal Ulcer Patients Presenting to a Hospital in South India. Indian Journal of Ophthalmology, 47, 15-18.

[14] Omolase, C.O. and Mahmoud, A.O. (2008) Perceptions of Nigerian Ophthalmologists about Traditional Eye Care Practice in Nigeria. African Journal of Medicine and Medical Sciences, 37, 255-259.

[15] Ukponmwan, C.O. and Omuemu, V.O. (2011) Knowledge and Attitude of Rural Dwellers to the Use of Traditional Eye Medication. Journal of Hainan Medical University, 17, 1-6.

[16] Yorston, D. and Forster, A. (1994) Traditional Eye Medicines and Corneal Ulceration in Tanzania. Journal of Tropical Medicine and Hygiene, 97, 211-214.

[17] Courtright, P., Lewallen, S., Kanjaloti, S. and Divala, D.J. (1994) Traditional Eye Medicine Use among Patients with Corneal Disease in Rural Malawi. British Journal of Ophthalmology, 78, 810-812. http://dx.doi.org/10.1136/bjo.78.11.810

[18] Bialasiewicz, A., Shenoy, R., Thakral, A., Al-Muniri, A.A., Shenoy, U. and Al-Mughari, Z. (2006) Microbial Keratitis: A 4 Year Study of Risk Factors and Traditional/Complementary Medicine in Oman. Der Ophthalmologe, 103, 682-687. http://dx.doi.org/10.1007/s00347-006-1363-2

[19] Ajibode, H.A. (1999) The Prevalence of Blindness and Visual Impairment in Ikenne Local Government Area of Ogun State, Nigeria. Nigerian Journal of Ophthalmology, 7, 23-27.

[20] Oluleye, T.S. (2004) Cataract Blindness and Barriers to Cataract Surgical Intervention in Three Rural Communities of Oyo State, Nigeria. Nigerian Journal of Medicine, 13, 156-160. 
[21] Kovai, V., Krishnaiah, S., Shamanna, B.R., Thomas, R. and Roa, G.N. (2007) Barriers to Accessing Eye Care Services among Visually Impaired Populations in Rural Andhra Pradesh, South India. Indian Journal of Ophthalmology, 55, 365-371. http://dx.doi.org/10.4103/0301-4738.33823

[22] Resnikoff, S., Pascolim, D., Etya’ale, D., Kocur, I., Pararajasegaram, R., Pokharel, G.P. and Mariotti, S.P. (2004) Global Data on Visual Impairment in the Year 2002. Bulletin of the World Health Organization, 82, 844-851.

[23] Clendenin, C., CoVey, M., Marsh, M. and West, S. (1997) Eye Care Utilization Patterns in a Rural County in Ireland: Implications for Service Delivery. British Journal of Ophthalmology, 81, 972-975. http://dx.doi.org/10.1136/bjo.81.11.972

[24] Palagyi, A., Ramke, J., du Toit, R. and Brian, G. (2008) Eye Care in Timor-Leste: A Population-Based Study of Utilization and Barriers. Clinical \& Experimental Ophthalmology, 36, 47-53. http://dx.doi.org/10.1111/j.1442-9071.2007.01645.x

[25] Orr, P., Barron, Y., Schein, O.D., Rubin, G.S. and West, S.K. (1999) Eye Care Utilization by Older Americans. Ophthalmology, 106, 904-909. http://dx.doi.org/10.1016/S0161-6420(99)00508-4

[26] Nedgwa, L.K., Karimurio, J., Okelo, R.O. and Adala, H.S. (2005) Barriers to Utilization of Eye Care Services in Kibera Slums of Nairobi. East African Medical Journal, 82, 506-508. 